Psychology of Language and Communication 2012, Vol. 16, No. 1

VERSITAOPEN

DOI: $10.2478 / \mathrm{v} 10057-012-0006-8$

ORLY KAYAM, YAIR GALILY

Zinman College at the Wingate Institute, Netanya

\title{
FREEDOM OF SPEECH? \\ ISRAELI SUPREME COURT RULING 606/93 - KIDUM INITIATIVE INC. VERSUS THE ISRAEL BROADCASTING AUTHORITY. A RHETORICAL LANGUAGE ANALYSIS
}

\begin{abstract}
The article examines nine different rhetorical devices employed by two Israeli Supreme Court justices in their writing of the majority and minority opinions (Justices Dorner and Cheshin respectively) in the case of Kidum Initiative Inc. versus The Israel Broadcasting Authority which addressed the issue of freedom of speech versus good taste. Theoretical background and examples from the verdict are presented and discussed.

Key words: Israel, Supreme Court, freedom of speech, language analysis, rhetoric
\end{abstract}

\section{Introduction}

A layman might think that the legal language of lawyers and judges is dry and boring, but an examination of the rulings of Israeli Supreme Court justices shows that at least some of them use very picturesque speech to support their positions. In this article we will examine nine different rhetorical devices employed by two Israeli Supreme Court justices in their writing of the majority and minority opinions (Justices Dorner and Cheshin respectively) in the case of Kidum Initiative Inc. (hereafter Kidum) versus The Israel Broadcasting Authority (hereafter IBA). The devices that will be discussed are: figurative speech, citation, repetition, irony, abusive language, idiomatic expressions, alternative arguments, comparison, and rhetorical questions. The current article is an extension of the author's research and

Address for correspondence: Yair Galily, The Zinman College for Physical Education and Sport Sciences at the Wingate Institute, Netanya 42902, Israel, e-mail: galiliy@wincol.ac.il; Orly Kayam, e-mail: orlyka@wincol.ac.il 
subsequent book On the scales of justice (Kayam, 2011) which addressed rhetorical features in legal language.

Kidum, a Hebrew word which means advancement or promotion, is a company that offers courses to young people to prepare them for matriculation and psychometric examinations. There are a number of such private companies competing in the Israeli marketplace. Kidum's marketing slogan is "Go Excel" which in Hebrew, not only rhymes with but sounds very much like "Go screw yourself", קיידזת דל אל Kidum bought advertising on the radio using this slogan. The IBA station manager rejected the commercial on the grounds that the slogan did not meet the criterion of good taste.

The case made it to the Supreme Court where it was heard by three justices: Justice Dorner and Justice Cheshin who wrote the ruling, and Justice Bach who joined them but did not write. It was Justice Dorner's position that there was no justifiable reason to reject the broadcast. Justice Cheshin held the minority opinion that the IBA station manager was within his rights to reject the broadcast. In this article we will show how each of these two justices: rolled up their sleeves, left no stone unturned, and enlisted a variety of rhetorical devices to prove the rightness of their path.

\section{Method}

In this article we chose to present one specific verdict: Israeli Supreme Court verdict 606/93 - the Kidum verdict. This case presents conflicting views on freedom of expression and illustrates the approaches and methods used by Israeli Supreme Court justices to present their arguments and the wide range of rhetorical devices they employ to support their position. We believe that this verdict is very instructive from a rhetorical standpoint, and that much can be learned about the art of how Israeli Supreme Court justices make use of various techniques to present their views.

\section{Theoretical Background}

The term rhetoric has yielded numerous definitions dating back to the ancient Greeks who developed its theory - the Theory of Rhetoric. Aristotle, Cicero and others devoted well-known and famous compositions to it (see Aristotle, 1932, 1954; Cicero, 1986). One of the great Greek philosophers, Aristotle, defines rhetoric as "the art of investigation of the means of persuasion that can be used in various circumstances." He states that there are two kinds of means of persuasion - one relates to those things that are self-evident and require no proof and the other to those that require proof. He also claims that there are three types of arguments:

1. Arguments that stem from the personality of the speaker (Ethos) and are based on his credibility. 
2. Logical arguments (Logos), which are meant to prove the speaker's point or to give the impression that the point has been proven.

3. Emotive arguments (Pathos), which aim to create a particular mood in the listener.

Other definitions of rhetoric include Brooks and Warren's (1970), defining rhetoric as "the art of using language effectively," Pearlman's (1984), referring to it as "the art of soliciting and persuading people," and following in Aristotle's footsteps, Landau (1988) goes further to divide the linguistic study of rhetoric into two areas:

1. Stylistic Rhetoric - which addresses the emotions and includes means of persuasion from the dictionary, semantics and syntax and

2. Rhetorical Argument - which addresses reason and includes logic and pseudologic, most of which are from the area of discourse analysis.

Researchers in the field of rhetoric differentiate between two types of persuasion: convincing, which appeals to one's sense of logic, and persuading, which appeals to one's emotions. Landau points out that the difference between convincing and persuading is expressed, among other things, in that with convincing, the speaker is interested in convincing the listener of the truth of his or her arguments as they are determined by the intellect, while with persuading, the speaker is interested in getting the audience to agree with his or her position, an audience of listeners being a key concept in rhetoric (Gitay 1991, 1996; Speigel, 1973).

\section{Rhetorical Devices}

The following section presents the theoretical background of each of the nine rhetorical devices along with examples taken from the judgment.

\section{Use of Figurative Speech}

Figurative speech is the use of images and metaphors to express ideas. Landau (1988) says that the main function of figurative speech is to express the requested message in a picturesque and tangible way that will be absorbed by the listener's emotions rather than their thoughts. The impact of figurative speech is very strong because the message is made clear and tangible, and yet direct. When using figurative speech, complex ideas can be expressed in a concise manner.

The most prominent form of figurative speech is the metaphor: A metaphor has a double meaning; it transfers the meaning from one semantic field to another semantic field; or it is a word or group of words that is given a second broader meaning (Nir, 1978). In literary theory, a metaphor is a word or group of words which have been given a different meaning that is broader than their dictionary meaning (Ochmani, 1976). Tzarfati (1978) adds that the metaphor spices up picturesque speech, making it more forceful, and is thus of primary importance in 
literary writing. The power of the metaphor is its ability to bring alive, renew and strengthen the impact of the message. A successful metaphor will leave a strong impression on the listener.

In her opening remarks Justice Dorner chooses to describe commercial expression in such figurative language as "step-child" and "flesh of his flesh." She uses images from family relationships to bring commercial relations closer to our hearts.

Justice Cheshin also uses figurative speech in his opening remarks: “...it appears that my colleague finds it fitting to launch an entire naval fleet headed by the flagship..." The image of the naval fleet tells the audience that this is war and the flagship in this war is freedom of speech, one of the cornerstones of democracy, the heaviest possible artillery.

Justice Cheshin uses an additional metaphor to describe freedom of speech, depicting it as a massive tree whose roots penetrate down into the earth until they meet rock and whose crown is tall, thick, and wide and which none would ever consider cutting down or even trimming. Thus Justice Cheshin describes how strong and deep-rooted the principle of freedom of speech is.

\section{Use of Citation}

In general, using quotes as a source of authority is one of the most frequent methods of expressing a convincing argument. Weddle (1978) says that this rhetorical technique is very prevalent in arguments, advertising, political speeches, trials, used by rabbis and so on. Landau (1988) writes that the appeal to authority reinforces the speaker's position and gives credence to it as if the authority of the one being quoted is transferred to the speaker and therefore provides proof of the rightness of his words.

A speaker may choose to incorporate phrases, verses, sayings, idioms, expressions and proverbs on stylistic grounds, to embellish his text, for lyrical beauty, or even out of habit. However, quoting from Jewish holy and literary sources serves as an additional function rather than just the stylistic one; the quote serves the speaker in that it clarifies the intent in a concise and precise manner while transferring to the new context the atmosphere and the situation that is described in the original text. The speaker need not always quote an entire verse from the source, but can rather use certain elements from the passage, such as the vocabulary or structure in a clear manner so that there is no doubt that his reference was to the verse itself.

Kayam (2011) and Livnat and Kayam (2004) contend that building on, quoting or referencing "giants" (a term meaning any famous public figure held in high esteem) is an encompassing rhetorical device, filling many varied roles, such as reinforcing the speaker's position, presenting and promoting information, stylistic ornamentation, etc. These may have added rhetorical value when used as argumentative rhetorical devices or stylistic means of persuasion, where the aesthetic pleasure, the emotion that they arouse in the listener and the atmosphere created can significantly contribute to the work of persuasion. 
Justice Dorner brings in examples from around the world and from Israeli case law to prove that commercial expression belongs to freedom of expression. Justice Dorner knows that if she succeeds in proving this point it will be difficult to reject the ad, because infringing on freedom of expression is in effect a blow to democracy. This is the logic behind her approach. To prove her point she uses a number of techniques. She argues that there are precedents in Israeli case law that support her position and that hers is the accepted position in the rest of the world. If the rest of the world believes this to be true why should we think differently? Here we see the technique of reliance on external sources (petition to authority and comparison with sources of authority).

\section{Rhetorical Repetition, Rhythm or the Parallel Structure}

Persuasive texts are characterized, among other things, by unique syntax structure whose purpose is to influence the listener. One way to achieve this end is by using a specific linguistic structure - the parallel structure. The parallel structure contains at least two elements equal in their internal structure or in their syntactical function in the sentence. Researchers attribute rhetorical advantages to the use of parallel structures. Hughes and Duhamel (1962) contend that ideas can be effectively transmitted by the use of parallel sentences. They add that the parallel individualizes the style of the speaker, emphasizes ideas, and clarifies the relationship between the ideas.

Brooks and Warren (1970) postulate that proper use of parallelisms can turn them into a very powerful rhetorical tool, where they emphasize and highlight ideas and create a debate between them. Shilo (1996) notes that repetition is a speaker's tool to present his ideas in a prominent or directed manner, making his words more persuasive. Landau (1988) notes that repetition eases the dialog process by intensifying the verbal redundancy rate which moderates the flow of new information. Maadia (1985) points out that the syntactic parallel influences listeners and enables them to absorb messages more effectively and retain those messages for longer. She adds that this rhetorical structure allows listeners to draw logical analogies and anticipate what will follow.

An important component of parallelism structures is rhythm, to which Landau (1988) attributes great importance. She writes that the tendency to associate rhythm with poetry is natural, but points out that it is found also in prose and public speeches.

Justice Dorner's arguments are arranged in such a way as to create a syntactical repetition which creates a rhythm: “...in Canadian law,...in international law,... In European convention" which awakens emotions and aesthetic pleasure in the listener. These elements can be used as means of persuasion.

And if any doubt remains, Justice Dorner states clearly: “...commercial expression is an outgrowth of freedom of expression." 


\section{Use of Irony and Abusive Language}

According to Quintilianus (in Weizman, 2000), irony is generally identified as having a hidden reversed meaning. This definition does not cover all cases, as irony does not necessarily involve reversed meaning. Weizman states that there are different views regarding the concept of irony. Grice (1975) sees irony as conversational implicature, Clark and Gerrig (1984) as pretense, and Spreber and Wilson (1981) as reverberation.

Justice Cheshin opens his remarks with a light tone of irony in the face of Justice Dorner's massive attempts at persuasion; he says: "...to buttress her position she enlists support from all corners of the globe." He continues apologetically: "I am left, much to my regret, no alternative but to go to battle."

In Hudson's The language of modern politics (1978) abusive language is defined as "injurious speech, reviling, execration." Landau (1988) raises two questions: Does abusive language include only direct expressions or is it also an indirect means of expression? After all, indirect means of expression such as paradox or irony can be even more hurtful than a juicy curse. Is abusive language only the use of specific words, or can it use other means of expression? Abusive language can include expressions larger than a word or even a sentence. Abusive language is expressed through confrontational speech, that is, when spoken, social conflict results between the speaker and the listener. This form of speech includes protest, admonishment and blame. The effect of the abuse is increased when it is accompanied by additional rhetorical devices, such as irony and metaphor.

Justice Cheshin says: "Justice Dorner makes improper use of the concepts of freedom and liberty" - we have here an example of abusive language: Justice Cheshin "accuses" Justice Dorner of improper use in mixing two unrelated issues. He inserts a hint of a verse from Psalms: "to set petty people with giants." He's alluding to Psalms chapter 113 verse 8: "to set him with princes, even with princes of his people." Except that in Psalms, the reference is to a worthy deed and here it is an unworthy deed. Justice Cheshin concludes by minimizing the issue saying that this is a minor issue of little value, truly trivial, and adds that this is not an issue for the Supreme Court.

Justice Dorner attacks Justice Cheshin's argument minimizing the issue by asking a rhetorical question: "And if commercial expression is not given value even in light trivial matters, then what significance and value is left to it?" Justice Dorner warns of the loss of value and significance of freedom of commercial expression.

\section{Use of Proverbs and Idiomatic Expressions}

An idiom is defined as a combination of words whose expression may differ from the meaning of the individual words of which it is composed (Even Shoshan, 1988). 
The Hebrew language is sprinkled with idioms, proverbs and word combinations that originated in ancient times. Some were in common usage in the Biblical and Talmudic periods and they are used in a similar fashion today. Others originally appeared at face value but in time were transformed into metaphors (Elon and Sorek, 1990).

Shohat (1928) writes that an idiom can be recognized in three ways: by its form, by its content and by its usage. The idiom is a linguistic manifestation of the intertwining of language and literature.

Nir (1978) says that the use of an idiom is a shorter, quicker way to express an idea. The idiom succeeds in expressing an idea with all the associations that are attached to it. Idioms are found in many fields, notably literature and public speaking, and are often an essential part of superior style.

Landau (1988) writes that collocation is any lexical unit with a given meaning that combines with a small group of words with a common semantic denominator having identical syntactical function. The lexical unit together with the group of words creates a limited collocation.

An examination of rulings of Israeli Supreme Court justices shows extensive use of idioms and expressions. They like to spice up their verdicts with references to Jewish sources as well as modern literature. The justices' language contains great linguistic wealth and their writings incorporate verses and segments of verses, famous sayings and pearls of literature adapted to the verdict. The average reader of the sources who reads the verdict cannot help but be aware of the deep knowledge of the justices and the influence of the sources on their writings (Kayam, 2011).

In addition to proverbs cited elsewhere in this article, Justice Cheshin hurries to placate with language saturated with idioms and collocation, "on guard day and night," and returns to his argument that they should discuss only important matters, using a biblical expression from Jeremiah which means "to separate the wheat from the chaff."

\section{Use of Alternative Argument}

The alternative argument is a technique that incorporates both logic and emotion to present opposing arguments and to persuade and convince the listener of a particular argument that the speaker supports. This technique includes sentences that from a formal-grammatical perspective are considered conditional sentences, and in their structure a concessive clause is hidden. Ornan (1971) writes: “...a concessive clause is a conditional sentence the content of its ending being the opposite of the content of its beginning."

The argument is built as follows: I believe $\mathrm{X}$; you reject $\mathrm{X}$ and believe $\mathrm{Y}$; or you don't believe $\mathrm{X}$ because of $\mathrm{Y}$; (implicit assumption: I am prepared to accept $\mathrm{Y}$ ) but also if / will even agree with you and accept $Y$; there is a problem with $Y$ or $Y$ is not good and so on and so forth; conclusion (explicit and implicit): $Y$ is not acceptable therefore X must be accepted. 
Use of the alternative argument is widespread in all forms of convincing and persuading, including legal language. This technique has great rhetorical power in that it involves goodwill, readiness and openness (seemingly or not seemingly) to accept the position of "the opponent," except that instead of rejecting and refuting the opponent's position, that position is shown to be problematic (for one reason or another) and therefore not good, in other words it cannot be accepted. At this point it is easier to get one's own position accepted. Use of the alternative conditional that includes concession allows for expressing the alternative argument, for the alternative conditional containing concession represents a hypothetical situation. Contrary to a true concession clause, where it is reasonable to assume that the argument is true, an alternative conditional does not assume the argument to be true. In fact use of this structure in most cases is for rhetorical needs, as the speaker in most cases has no intention of accepting the argument and is only interested in refuting the opposing argument and justifying his/her own argument.

Justice Dorner believes that the slogan has no sexual innuendo. She says the slogan's intent is simply to encourage excellence. Though she agrees that there are connotations (only that and nothing more) of a swear word, the intent is "only" to attract the attention of a young audience, a kind of prank.

Here are some examples from the verdict:

Justice Dorner says that she doesn't think the slogan is offensive to good taste (argument X), but even if it is (implicit assumption: I am prepared to accept Y) there must be an examination as to whether it is sufficiently offensive to justify disqualification (explicit and implicit conclusion: $\mathrm{Y}$ is not acceptable therefore $\mathrm{X}$ must be accepted).

Justice Cheshin does not agree that the meaning of the slogan is straightforward. He does not accept Justice Dorner's minimization of the slogan, her view that the slogan is a sort of prank. He says "The expression leads of itself to obscenity, and the station manager was allowed to reject it."

As for her argument that perhaps the slogan is offensive, but even if that is the case, it is not sufficiently so to warrant being rejected, Justice Cheshin is adamantly opposed and resorts to abusive language: "Freedom of expression is not reckless speech and is not lawless speech. The expression was rejected because it does not meet a worthy level and it leads to obscene language, it is a vulgar and coarse expression." Justice Cheshin's argument is massive and forthright, he increases the intensity till he reaches a peak with a beautiful proverb "His voice was raised from one end of the country to the other"... "it would strike the ears even of one who was used to it" (and there aren't many, according to Justice Cheshin in another place) "and their ears would ring" (that is, the majority of the population). In other words, woe to the ears that hear this!!!! 


\section{Use of Comparison}

Weddle (1978) writes that comparison is the act of placing two things or two groups of things opposite one another and measuring them. Hughes and Duhamel (1967) formulate the basic equation in the following logic format: A is like B (as regards $\mathrm{X}$ ), $\mathrm{X}$ is true for $\mathrm{B}$, therefore (it is most probable that) $\mathrm{X}$ is true also for $\mathrm{A}$. The act of comparison has two different outcomes and they are: analogy, meaning pointing out one or more ways in which the two are similar, and contrast, meaning pointing out one or more ways that the two are different. Weddle adds that analogies are widely used in language. Copi (1982) writes that the analogous argument is the most common of the inductive arguments. Most of our daily deductions are made by way of analogy. Perelman (1984) writes that analogy does not assume a relationship of equality but asserts a relationship of similarity. Copi (1982) differentiates between argumentative analogies and non-argumentative analogies, which are used for literary purposes like metaphors and parables.

Weddle (1978) writes that it is necessary to differentiate between an analogy that asserts similarity between two things and argumentative analogy where conclusions are drawn based on those similarities. Landau (1988) adds that also non-argumentative analogies have great rhetorical power, when their purpose is to transmit a subjective emotional characteristic to the object of comparison. The analogy, Landau writes, is both a logical and emotive rhetorical device. The common ground between argumentative and non-argumentative analogies is the rhetorical aim to characterize the object of the comparison or to argue opposing arguments by means of comparison to another object. The difference between the two forms is that the non-argumentative analogy appeals to emotion, and attempts to influence the listener by means of their emotions, while the argumentative analogy appeals to reason despite the fact that from a purely logical standpoint there is no deductive validity.

Justice Dorner uses the technique of comparison: First the "you too" technique, the radio broadcasts other vulgar ads. You did it in the past, why shouldn't you do it again? This demands activating the "law of fairness," the "law of reciprocity and equality" that demands equal outcomes for equal behaviors.

Justice Dorner continues and says that the ad is broadcast on television's channel two without interference. By such a comparison to other communication media (comprehensive, widely circulated) she strengthens her position, for if other larger, more respected communication media agree to broadcast the ad, then this supports the rightness of her position.

\section{Use of Rhetorical Questions}

Gray (1977) defines a rhetorical question as an explicit question which is not intended to elicit an explicit answer. A rhetorical question does not have different linguistic characteristics than a regular question but can be identified by pragmatic 
and semantic devices (see Landau, 1988). The rhetorical question provides information and generally does not request it. In fact it has the significance of declaration. Quirk (1976) adds that the question takes on the meaning of a bold declaration. They say that a positive rhetorical question makes a bold negative declaration and a negative rhetorical question makes a bold positive declaration. The goal of the speaker who asks the question is to cause the listener to infer the message he wishes to impart. The listener will be aided in deciphering the meaning of the rhetorical question by the pragmatic circumstances of the context.

In his reply to Justice Dorner's comparison with other media Justice Cheshin puts an end to Justice Dorner's argument by saying: “... And if other broadcasts use vulgar language..." (he is not sure that they do use such language) and he continues with a rhetorical question, ensconced with reproach and arrogance, "...should we then also do so in our case?"

He also presents the answer of the broadcasting authority personnel to Justice Dorner, who also replied with a rhetorical question accompanied by protest “....and so must we sink to the lowest level that is acceptable elsewhere?"

Justice Cheshin concludes his remarks by strengthening the previous rhetorical questions with an additional rhetorical question that represents the peak of the alternative argument: "...and is it not an offense to good taste only because others broadcast similar commercials?” Here he uses Justice Dorner's argument to prove his own point. That is, the fact that others are also broadcasting is offensive to good taste.

As previously stated in the section on abusive language above, Justice Dorner also makes use of rhetorical questions when she asks: "And if commercial expression is not given value even in light trivial matters, then what significance and value is left to it?"

\section{Conclusion}

In this article we aimed to discuss the rhetorical techniques used in Israeli Supreme Court verdicts from the perspective of one specific verdict: The Kidum case, verdict 606/93. This verdict is representative of the approaches and methods of Israeli Supreme Court justices in terms of the rhetorical devices they use to support their arguments. The verdict includes examples of a wide range of rhetorical devices used by each of the justices in order to prove their point and persuade. We see how Justices Cheshin and Dorner use persuasive means and confront each other till the reader receives the impression that a "war of giants" is taking place.

It was surprising to discover that the justices used expected rhetorical devices like logical arguments alongside less expected rhetorical devices like stylistic and pseudo-logical devices.

In the end it was not Justice Cheshin's position but Justice Dorner's that was accepted by a majority of the justices. Justice Cheshin concludes his remarkable 
speech using his unique style incorporating a hypothetical conditional clause and word play (in Hebrew "heard but not listened to" are two forms of the same root (העמשנ אלו העמשנשמ): "Had my opinion been accepted, the end result would have been different: we would have cancelled the order nisi and rejected the appeal. But since my opinion was heard but not listened to, the case rests."

The original Hebrew verdict can be found at:

www.nevo.co.il/Psika word/elyon/PADI-NG-2-001-L.doc

\section{References}

Aristotle (1932). The rhetoric (trans. Lane Cooper). Englewood Cliffs, NJ: PrenticeHall.

Aristotle (1954). Rhetoric and poetics. Vol. XI. Oxford: Clarendon Press.

Brooks, C. \& Warren, R. (1970). Modern rhetoric. New York: Harcourt, Brace and World.

Cicero (1986). Selected writings (ed. by M. Barash). Jerusalem: Massad Bialik Press. Clark, H.H. \& Gerrig, R. (1984). On the pretense theory of irony. Journal of Experimental Psychology: General, 113 (1), 121-126.

Copi, I.M. (1982). Introduction to logic. New York: Macmillan.

Elon, A. \& Sorek, H. (1990). Idioms exceptions to the rule [in Hebrew]. Tel Aviv: Eretz Yisrael Museum.

Even-Shoshan, A. (1988). The new dictionary [in Hebrew]. Jerusalem: Kiryat Sefer. Gitay, Y. (1991). Isaiah and his audience. Assen/Maastricht: van Gorcum.

Gitay, Y. (1996). Rhetoric and its importance in the media. Lecture at the $23^{\text {rd }}$ annual conference of the Israeli Association for Applied Linguistics, Technion, Haifa.

Gray, B. (1977). The grammatical foundations of rhetoric. The Hague: Mouton.

Greenbaum, S. (1970). Verb-intensifier collocations in English. The Hague: Mouton.

Grice, H.P. (1975). Logic \& conversation. In P. Cole \& J.L. Morgan (Eds.), Syntax \& semantics. Vol. 3 (pp. 41-58). New York: Academic Press.

Hudson, K. (1978). The language of modern politics. London: The Macmillan Press. Hughes, R.E. \& Duhamel, P.A. (1962). Rhetoric. Englewood Cliffs, NJ: Prentice-Hall. Kayam, O. \& Livnat, Z. (2004). Quotation as a rhetorical device in Israeli court judgment [in Hebrew]. Hebrew Linguistics, 54, 37-53.

Kayam, O. (2011). Rhetoric on the scales of justice [in Hebrew]. Tel Aviv: Assif.

Landau, D. (1979). From metaphor to symbol [in Hebrew]. Ramat Gan: Bar-Ilan University.

Landau, R. (1988). The rhetoric of political speech in Israel [in Hebrew]. Tel Aviv: Akad Press.

Maadia, M. (1985). Modern political speech - Personal style or register? Masters thesis [in Hebrew]. Ramat Gan: Bar-Ilan University.

Nir, R. (1978). The semantics of the New Hebrew [in Hebrew]. Tel Aviv: Amichai Press. 
Ochmani, A. (1976). Lexicon of literary terms [in Hebrew]. Tel Aviv: Sifriyat Hapoalim.

Ornan, U. (1971). Hebrew grammar syntax. Encyclopedia fudaica, 8, 140-175.

Perelman, H. (1984). The kingdom of rhetoric [in Hebrew]. Jerusalem: Magnus Press.

Quirk, R. (1976). A comprehensive grammar of the English language. London: Longman.

Shilo, G. (1996). Characteristics of Hebrew theoretical writing [in Hebrew]. Ramat Gan: Bar-Ilan University.

Shohat, N. (1928). Hebrew expression [in Hebrew]. Jerusalem: Kiryat Sefer.

Speigel, N. (1973). Art of persuasion - The speaker and his audience [in Hebrew]. Jerusalem: Magnes Press.

Spreber, D. \& Wilson, D. (1981). Irony and the use-mention distinction. In P. Cole (Ed.), Radical pragmatics (pp. 295-318). New York: Academic Press.

Tzarfati, G. (1978). Hebrew semantics [in Hebrew]. Jerusalem: Rubenstein Press. Weddle, P. (1978). Argument - A guide to critical thinking. California: Mcgraw-Hill. Weizman, E. (2000). Irony in news discourse [in Hebrew]. In O. Rodrigue-Schwarzwald, S. Blum-Kulka, \& E. Olshtain (Eds.), Rafael Nir jubilee book: Studies in communication, linguistics and language teaching (pp. 237-248). Jerusalem: Carmel Press. 